\title{
Improving the impact of digital cultural heritage : system, content and users' challenges
}

Pierluigi Feliciati

Researcher and lecturer of LAIS, university of Macerata, Italy

\begin{abstract}
Résumé : Dans le domaine de la culture, l'impact du patrimoine numérique sur la société est stratégique et constitue la qualité intrinsèque des ressources elles-mêmes. La tendance actuelle incite les institutions GLAM (acronyme anglais pour « Galleries, Libraries, Archives and Museums », en français « Galeries, Bibliothèques, Archives et Musées ») à dépasser la conception du patrimoine comme 《 Beau » valable en soi, accessible seulement à quelques spécialistes, et au contraire à favoriser des collisions proactives avec les besoins des communautés, leurs perceptions, leurs choix. Ainsi, étant donné que les éléments cruciaux pour un projet de patrimoine digital semblent être les contenus auxquels il donne accès, les fonctionnalités disponibles, et les usagers, il devient essentiel de tenir compte des besoins et attentes de ces derniers, qu'ils soient explicites ou non, pour assurer un service convenable.Cette contribution présente brièvement les principaux problèmes et les possibilités offertes par une structuration des études d'utilisateurs de produits culturels numériques, en se concentrant sur le système, les contenus et les utilisateurs, qui constituent les trois pôles de cette structure interactive.
\end{abstract}

Mots-clés : patrimoine culturel numériques ; usagers ; qualité des usages ; systèmes d'information culturelle

La mia operazione è stata il più delle volte una sottrazione di peso; ho cercato di togliere peso ora alle figure umane, ora ai corpi celesti, ora alle città ; soprattutto ho cercato di togliere peso alla struttura del racconto e al linguaggio. Italo Calvino, Lezioni americane, 1988, Incipit.

\section{Introduction}

The Italian writer Italo Calvino in the fall of 1985 wrote for the Charles Eliot Norton Lectures at Harvard ${ }^{1}$ Six Memos for the Next Millennium. Six lectures, each dedicated to an essential value of literature for the coming millennium : lightness, quickness, exactitude, visibility, multiplicity. The sixth lecture, never written because of author's 10].

1. See https://en.wikipedia.org/wiki/Charles_Eliot_Norton_Lectures [checked on 2018, november, 
death, after the first hypothesis of openness is known to be dedicated to consistency (Calvino, 1988). Reading again those precious pages today, after more than twenty years of life of the World Wide Web, they seem to contain a fascinating and evocative value for those who today reflect on the quality of information resources on the Worldwide Network. The World Wide Web and the mobile networks, it is quite evident, have evolved into a lighter, quicker, potentially more exact, extremely visible, open and multi-channel docuverse ${ }^{2}$.

However, what has still to be widely studied is its impact in terms of service for final users. In other words, the evaluation of the quality of use of digital environments is often conceived as a subsidiary activity, external to the stream of projects' development $^{3}$. Nowadays the issues related to the quality of digital resources are intensely explored by scholars and stakeholders, and partially determined in specific rules, for example in the European Digital Agenda ${ }^{4}$ determinations.

In the cultural domain, the impact of digital heritage on society is considered more and more an essential task to be achieved, strategic as well as the intrinsic quality of resources themselves ${ }^{5}$. The turning upside-down of the traditional relationship between heritage and citizens statued in the Faro Convention ${ }^{6}$ opens up new, stimulating challenges for GLAM institutions ${ }^{7}$, forced to go over the conception of heritage as « beauty », fully usable just for few, sensible experts, towards the pro-active collision with communities' needs, perceptions and choices. In this dynamic exchange, the access and effective (re)use of digital resources takes on crucial importance. After more than a decade of huge networking and sometimes hasty accumulation of millions of resources, some signs are revealing a renewed attention to the necessity of a more careful selection and a more strict implementation of the right technical standards, to ensure the essential interoperability and the long-term access to the brand new precious (and expensive) digital resources.

From another point of view, the social impact of projects depends mostly on their overall quality, thus mostly on their final users' satisfaction. Some help in analyzing the complex concept of quality - a perceptual, conditional, and somewhat subjective attribute - for digital cultural heritage projects may come from the definition provided by the standard ISO/IEC 9126-1 :2001 ${ }^{8}$. Quality is « the capability of the software product to enable specified users to achieve specified goals with effectiveness, produc-

2. The docuverse paradigm was created by Ted Nelson in 1974 , in the framework of his project Xanadu, http://www.xanadu.net/, to define a « global distributed electronic library of interconnected documents » [checked on 2020, june, 10].

3. On social impact of cultural project see the recent Dal Pozzolo (2015).

4. See http://ec.europa.eu/digital-agenda/en, in particular the Communication from the Commission to the European Parliament, the Council, the European Economic and Social Committee and the Committee of the Regions, Brussels, 19/5/2010 (COM (2010) 245) [checked on 2020, june, 10].

5. See for example the topics of Achieving Impact : Socio-economic Sciences and Humanities (SSH) in Horizon 2020, an international conference organized in Athens on February 2014 by NET4Society, to inform about « opportunities that exist in Horizon 2020 and to help prepare the Social Sciences and Humanities research community for the new EU program for Research \& Innovation » Horizon 2020, http://www.achievingimpact2014.eu/ [checked on 2018, november, 10].

6. Council of Europe, Framework Convention on the Value of Cultural Heritage for Society (Faro Convention), CETS No.199, Faro, 27/10/2005. https://www.coe.int/en/Web/conventions/full-list//conventions/treaty/199 [checked on 2020, june, 10].

7. Galleries, Libraries, Archives and Museums.

8. ISO/IEC 9126-1 :2001. Software engineering — Product quality. Part 1: Quality model. 
tivity, safety and satisfaction in specified contexts of use ». This definition highlights the fact that the quality of a software product (like any Web or mobile interfaces) lies not on the absence of faults, richness of functions, or on its technical innovation, but is merely based on the extent of which products are usable and accessible according to the needs of the users in the context of use.

If we assume that there are three core elements in a digital cultural heritage application, the content it makes available, the services it provides, and the users, we can't help to admit that understanding the needs of the users, whether these needs are explicit or not, is core to the delivery of any good service, including digital cultural heritage.

The reliability of digital resources represents a basic criterion to be linked both to their technical quality and their strictly informational attributes. These two properties - technical and content - are in the world of online information- with respect to the analog world - totally interdependent. While the informative quality in the strict sense does not pose major differences compared to the criteria of traditional assessment, with some differences explained below, the technical qualities of Web resources have strong effects on some basic issues like the satisfactory readability and the stability of resources, i.e. their reliability.

Cultural heritage digital environments, whatever their typology ${ }^{9}$, have a wide range of users including professionals, digital natives as well as general users. Their motivation and needs may deeply differ and one of the challenges in evaluating how digital cultural heritage has been perceived is to understand the specific points of view of the various communities. The identification of stumbling blocks and features which are not satisfying users' expectations is aimed not only to develop a clearer understanding of users and to serve them better but also to sustain a steady user community, so is part of a strategy of support and development of projects.

To better present the complex issues related to the interaction between users and digital cultural environments, in this paper we adopt the framework logics of the Interaction Tryptich Model (Fuhr, Tsakonas et al., 2007 ; Tsakonas and Papatheodorou, 2008), an effective theoretical framework specially designed to contribute to a model of evaluation of digital libraries (Tsakonas, 2012).

This model is based on the three pillars every digital environment is based upon, consisting of content, users, and the system, and considers the interactions between them, as the core criteria of evaluation. If the relation between system and content relates to efficiency and performance, the interaction between users and content concerns, briefly, the utility. Finally, between the user and the system, the relation may be included in the dimension of usability, the specific domain of evaluation of the quality of use (see below). Each of these relationships refers to specific macro-categories of evaluation : it is quite different to measure systems' performance (accuracy, relevance, time responses, etc.) than to organize studies on the utility of projects, i.e.

9. We refer, using a generic terminology, to digital library, electronic catalog, museum or library or archive Website, virtual museum, virtual exhibition, archive online, portal etc. See Hazan and Hermon (2013) ; Chowdhury and Chowdhury (2002); Dobreva, O'Dwyer and Feliciati (2012); Patel, White, Walczak and Sayd (2003); Natale, Fernández, López (2012); Feliciati and Alfier (2014). 
evaluating the effective satisfaction (foreseeable or actual) of users, measuring content coverage, completeness, relevance, format issues, analytical level, etc. Finally, we have considered the exploration of interface usability, consisting of its ease of navigation and operation, the terminology used, the layout effectiveness and agreeableness, etc.

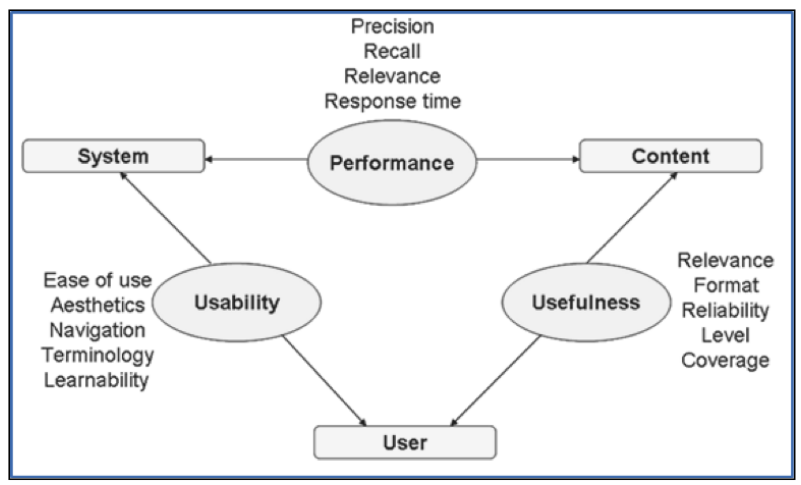

FIgURE 1 - Interaction triptych model (Tsakonas and Papatheodorou, 2008)

This paper is dedicated to present - adopting as a logical path the just mentioned Tryptich model - the more relevant issues to be faced in order to improve the impact of digital cultural heritage projects, considered just from the predictable point of view of final users, obviously strictly depending on their entire development cycle.

\section{System's issues}

The first category refers to the system, i.e. to all the hardware and software components essential to ensure the delivery of cultural content for final users, through digital technology. The development, prototyping, testing and delivery of the entire set of technical components are typically responsibility of the Information and Communication Technology (ICT) staff. From the point of view of system evaluation, the macro-criterion of performance is generally measured adopting specific software procedures. They detect the interaction of the system response to conditions of real or simulated massive use, to establish the crashing thresholds after data access and retrieval, both testing the system during the formative phase, and while the public delivery of the service. As it is evident, such operations are attributable to ICT professionals, internal or not to the project, even if a basic awareness about the importance of inserting these activities in the project life-cycle is usually in charge to coordinators. During the last decade, several models and handbooks were released to support cultural heritage professionals with some basic guidelines, even technical, sustaining their challenge to develop and manage the quality of digital applications ${ }^{10}$.

10. The MINERVA project, for example, from 2002 to 2008 produced several open access documents, in various European languages, with the goal « to facilitate the creation of added value products and services at European level, to improve awareness of the state-of-the-art in the sector, to contribute to the overcome of fragmentation and duplication of digitization activities of cultural and scientific content and to maximize cooperation among the Member States »; see http://www.minervaeurope.org/publications.htm. Recently the Athena (http://www.athenaeurope.org/) and Athena plus (http://www.athenaplus.eu/) projects released more other up-to-date tools and guidelines about digital geographic information, persistent identifiers, 
Coming to the interface and its use by real users, some solutions are becoming more and more common in digital environments, with the multiple aim of increasing the interaction of users and creating designated communities, adopting the OAIS terminology ${ }^{11}$. Their importance in terms of social impact of digital cultural heritage is so critical that they should be considered in every project : I am referring to all the customized services available for registered users, save-for-later and re-aggregation tools, social tagging, comments, games, etc.

The quality macro-criterion governing the relationship between user and system - in the reference model we are adopting - is usability. But it's clearer to discuss this quality issue later, in the paragraph dedicated to users. Deepening the concept of system for digital cultural heritage, it is not easy to draw a classification, and the definitions adopted from time to time (digital library, virtual museum, portal, data source, Web site, digital edition, digital archive, archive online, etc.) do not always correspond to shared and accepted reference models. For sure, most of digital cultural heritage applications offer to distant users the opportunity to search, retrieve, select, choose, understand, share, and even save for later some sort of cultural content. This content could be both digital born and a reproduction of some existing artefact, document, idea or tradition. Having to face the issues opened by the search and retrieve activities, it could be suggestive to go back to their origins, and read the voice of an ancient philosopher :

Meno : And how will you enquire, Socrates, into that which you do not know? What will you put forth as the subject of enquiry? And if you find what you want, how will you ever know that this is the thing which you did not know?

Socrates : I know, Meno, what you mean; but just see what a tiresome dispute you are introducing. You argue that man cannot enquire either about that which he knows, or about that which he does not know; for if he knows, he has no need to enquire; and if not, he cannot; for he does not know the very subject about which he is to enquire (Plato, 380 B.C.E).

The basic question seems to be what we are really allowed to search in a digital environment, how (i.e. using what subjects, keys, words, filters, etc.) and especially in what measure we can distinguish among the search results. The goal of putting final users in the condition of searching and choosing easily is not just a matter of nice graphical layouts, as often perceived and proposed by ICT developers, but involves the quality of (meta)data, the logics of indexing and the ranking criteria, all issues asking the collaboration of content architects.

Other relevant issues related to system regard the support of the discovery of cultural digital resources in the Web, i.e. exposing the correct metadata so that the digital collections could be used and re-used by other applications and services. The adoption

content aggregation, cultural tourism, digital storytelling, multilingual terminologies management and digital exhibitions. [checked on 2020, june, 10].

11. Consultative Committee for Space Data Systems. Reference Model for an Open Archival Information System (OAIS). Washington, DC, http://public.ccsds.org/publications/archive/650x0m2.pdf [checked on 2020, june, 10]. 
of one or more of the protocols or interfaces available has to be considered surely as a technical question, but its edges and the very mission should be guided by all the project staff. Final users, humans or Web agents, could want to repackage and re-purpose the materials developed by digitization projects (for example, in other Websites, or in social networks), and this re-use should be facilitated by adopting the implementation of the right standards.

Another important issue related to system is the long time preservation of digital cultural content, to guarantee access to future users and to hold for long the value (cultural and economic) created after the investments. The society's needs to preserve the records of its culture over time imply that a failure to ensure long-term preservation « will damage future scholarship and weaken our scientific and cultural heritage »(Drijfout, 2001).

Preservation depends upon the documentation of all the technological procedures existing behind the creation of an object, taking in consideration that much of the critical information can be captured just in the phase of creation. Thus, it not just a question of choosing the best suitable file formats or media types. Instead, it is a fundamental responsibility for those who own and manage digital information content ensuring its long-term use and re-use ${ }^{12}$. This depends also upon some factors outside of the digitization process itself, like the continued funding and the changing of intellectual property rights However, there are technical strategies that should be adopted during the digitization process to facilitate preservation.

The last but not least issue concerning systems is open by the re-thinking of the global docuverse as a Web of data, whose links are rich and active and are understandable and processed by machines. According to the W3C Consortium, « The Semantic Web provides a common framework that allows data to be shared and reused across application, enterprise, and community boundaries ${ }^{13} \gg$. This approach goes over the conception of a world-wide network of documents inter-connected by links, and towards a network of Linked Open Data, whose content is atomized in information units representing any «thing in the world », concrete or abstract, expressed using semantic languages, so that automatic agents may understand and draw new conclusions. The semantic Web is no more an utopia, considering that in 2013 more than four million Web domains contained Semantic Web markup (Ramanathan, 2013).

\section{Content issues}

Obviously, content is the necessary entity to build up any service. Someone noticed (Filacchioni, 2006) that digital content, no matter if it is text, image, sound or video, could be sufficient, better if well-structured, to build a communication through a Web page. These elements, unlike layout and dynamic effects, could support the

12. See the UE Commission Recommendation (17 July 2012) on access to and preservation of scientific information (2012/417/UE), http://eur-lex.europa.eu/legal-content/IT/TXT/?uri=CELEX: $32012 \mathrm{H} 0417$ and the Revised strategy on UNESCO's contribution to the promotion of open access to scientific information and research, 20 October 2011, http://www.unesco.org/new/fileadmin/ MULTIMEDIA/HQ/CI/CI/images/GOAP/OAF2011/213342e.pdf [checked on 2020, june, 10].

13. World Wide Web Consortium (W3C). W3C Semantic Web Activity, 2011. http://www.w3.org/2001/ sw/. The term was coined by Tim Berners-Lee, James Hendler and Ora Lassila, in 2001 [checked on 2020, june, 10]. 
satisfaction of user experience but, in principle, are not to be considered essential. In our view, the quality of content is crucial to ensure usefulness to any digital cultural heritage application, and final impact depends from usefulness to the same extent than usability and system performance.

The role of cultural heritage professionals is asking more and more awareness on content engineering, in order to ensure that our representations of real world are not just scientifically complete and correct, but also technically well-formed, coherent, open, and interoperable with the current global state of the art.

The nature of digital cultural content is extremely various and not necessarily it is a form of representation or reproduction of analog cultural entities (pieces of art, documents, traditions, books, ideas, and so on). Indeed, it's more and more usual that cultural resources on the Web are digital-born, like descriptions, 3D reconstructions or digital art, or are related to real life but much more complex, blending together different information and media in the same resource (image, video, audio, text, applications, etc.). Furthermore, digital cultural content may differ depending on the cultural sector at its origin, so that, for example, an ancient document could be represented very differently by a librarian, an archivist or an art historian, and it's not rare to have quite diverse versions of the same cultural heritage piece, even inside the same portal.

Moreover, it is not so usual that policy makers adopt strategies based on the analysis of the expected impact of cultural digitized content on the designated communities, like common users, scholars, schools, universities and research centers, but also creative industries and cultural tourism operators ${ }^{14}$. A best practice in this sense was the UK DiSCmap project (Digitisation of Special Collections : mapping, assessment, prioritization ${ }^{15}$ ). Its primary goal was to study user's needs towards digitized special collections in the higher education institutions, by assessing the current landscape of digitization from the point of view of the needs of the researcher and teachers. The study was conducted by multiple methods to gather data: Web questionnaires, focus groups, interviews as well as social networking.

Thus, facing the issue of quality of digital cultural content seems to be a challenge not limited to its authorship, authoritativeness, or adherence to standards. The content quality in digital era depends mostly on the policy adopted during its production chain, including the organizational and the technical issues : « within the lifetime of a program, the technological environment changes and standards evolve. Programs should maintain awareness of all ongoing standards developments relevant to their operating context ${ }^{16} \gg$.

14. See for example the recent document produced inside the Athena Plus project, Digital Cultural Heritage and Tourism. Recommendations for cultural institutions, version 1.0, October, 2, 2014, http: //www.athenaplus.eu/getFile.php?id=428 [checked on 2020, june, 10].

15. The DiSCmap project was commissioned by JISC (Joint Information Systems Committee (JISC), http://www.jisc.ac.uk/ [checked on 2020, june, 10]) in 2008 to the Centre for Digital Library Research (CDLR) of the University of Strathclyde. The work on the project was completed between September 2008 and May 2009 by CDLR and CERLIM (The Centre for Research in Library and Information Management) at the Manchester Metropolitan University. For a presentation of its results, see Dobreva et al. (2009). On the topic of prioritization, see also Manžuch (2009), and Maceviciute and Wilson (2010).

16. A valid guideline to the management of digital cultural projects' life cycle is for sure the Technical Guidelines for Digital Cultural Content Creation Programs, edited in the context of MINERVA project 
Independently from the technical aspects, synthetically listed in the previous paragraph, some issues related to the « inner quality » of digital cultural heritage could be detected. First, the impact of granularity of content, i.e. its analytic level, is more and more crucial. For cultural heritage, the single piece of culture needs to be considered and presented in the framework of its several contexts : of production, of provenience, of conservation, of presentation, of digitization. The risk of cultural and semantic neutralization inherent in digital project is high. When the main goal of projects is concentrated on the offering of huge quantities, and the descriptive metadata adopted are simpler and simpler to quicken the digital objects production chain, the result could be an enormous quantity of isolated monads.

The concept of collection, which importance is out of discussion, is replaced by that of undifferentiated shopping malls, where the spell seems to come from the broadest choice of products instead of their cultural meaning. The context should be made up both of additional metadata and explicit and qualified relationships among single content units. The European project MICHAEL ${ }^{17}$, whose aim was to provide access to European digital collections, started from the premise that, in order « to describe these digital collections we also need information on the institutions that own them, the projects or programs in which they are created, the physical collections that were digitized and the services or products through which digital collections are made them available ${ }^{18} \gg$. In short, the goal of preserving the organizational and cultural context of digital cultural content has to be shared and achieved. The aim should be to record and transmit to our heirs the complexity of European culture, not made just of masterpieces, but of a diachronic network of local cultures and - in our times of distributed competence centers who invest their resources in creating the present heritage of digital culture : database, digital libraries, Websites, portals, et cetera.

To go forward in the series of issues regarding content, we cannot help to face the challenge of interoperability, i.e. the requirements to ensure usefulness, portability and durability of digital resources. It is actually a technical topic, but related with preservation and cooperation; present tendencies demonstrate how digital content spreads its huge potentialities while it's open to be connected and re-used in the Net.

To conclude, we already mentioned the Semantic Web and the Linked Open Data, and the issues related with content regarding on the one hand the adoption of proper metadata standards, on the other its « atomization », a process started from the very beginning of Internet (Aveney and Conneen, 1986) and now completed with the shift from the Web of information to the Web of data (as opposed to a sheer collection of datasets ${ }^{19}$ ). The effects of such atomization on cultural heritage content has still to be fully evaluated, considering also the risks quoted above about the possible loss of context. Anyway, we are abandoning quickly the classic database we were used to develop catalogs, i.e. collections « of information that is organized so that it can easily

and available in http://www.minervaeurope.org/publications/MINERVA $\backslash \% 20 T G \backslash \% 202.0$.pdf [checked on 2020, june, 10]. We refer to this document for all that regards technical and organizational issues.

17. Multilingual Inventory of Cultural Heritage in Europe http://www.michael-culture.org/ [checked on 2020, june, 10].

18. MICHAEL data model. Version 1.0, 2005_,_ http://www.michael-culture.org/images/dl_files/ MICHAELDataModelv1 0.pdf [checked on 2020, jünè, 10].

19. See http://www.w⿳亠丷厂彡.org/standards/semanticWeb/data [checked on 2020, june, 10]. 
be accessed, managed, and updated ${ }^{20} \gg$. The essence of database is to be made of data (aspects of reality modelled in order to supports processes), necessarily together with their applicable rules (metadata). The singular, atomic RDF statements about resources (in particular Web resources) are in the form of subject-predicate-object, much more similar to human reasoning. They open a brand new era, where links are qualified and automated software can store, exchange, use and re-use a huge mass of machine-readable authoritative data, enabling users to deal with the information with greater efficiency and certainty

\section{The role of users}

At least, it is useful to discuss about the final goal of any service, the quality - not just the degree - of user's behavior and satisfaction. We are currently living a sort of paradox : major institutions from the cultural heritage sector clearly emphasize the place of user evaluation and feedback analysis in digitization-related policies. But, to be honest, typically the decisions about aspects of digitization projects impacting on users are frequently taken without any direct involvement of real users. The wrong, idealistic conviction that cultural content is good, interesting, effective, clear, usable and attractive in itself has always produced bad exhibitions, inaccessible museums, elitist libraries and archives, such as unusable and almost useless digital environments.

So, the question is : how do we care for our users? The first pre-requirement to ensure users' satisfaction is the assurance of access to any content. This accessibility could be defined adopting the ISO TS $16071: 2002$ standard : a Web site is considered to be accessible when the informational content, navigational modes and all the interactive features present are accessible to all users, regardless of disabilities and independently of technology used to access the site and of the context in which they are working whilst accessing site ${ }^{21}$.

As regards usability and utility, taking them as the macro-requirements to ensure quality to the interaction between, respectively, users and system or users and content, the starting point could be the necessity to check their level of achievement by organizing evaluation activities including the involvement of users. The studies devoted to understand needs, expectations, and service perception of users, based on their direct or indirect involvement, are core to the building and delivery of a good Web service, especially in the cultural heritage sector. These studies could be scheduled both in the formative and in the ongoing phases of projects' life cycle (Dobreva, O'Dwyer and Feliciati, 2012, p. 247-253).

20. See http://searchsqlserver.techtarget.com/definition/database [checked on 2020, june, 10].

21. "The concept of accessible design ensures both "direct access" (i.e. unassisted) and "indirect access", meaning compatibility with a person's assistive technology (for example, computer screen readers) », https: //en.wikipedia.org/wiki/Accessibility [checked on 2020, june, 10]. To ensure accessibility many solutions are available since the very beginning of the Web (see in particular the Web Accessibility Initiative of the W3C, http://www.w3.org/WAI/ [checked on 2020, june, 10]), but it is useful to remind that both European Commission (http://ec.europa.eu/ipg/standards/accessibility/index en.htm [checked on 2020, june, 10]) and several European countries imposed specific rules for public Websites and services, while in the USA is active since 1973 the Section 508 of the Rehabilitation Act, https://en.wikipedia.org/wiki/ Rehabilitation_Act_of_1973\#Section_508 [checked on 2020, june, 10]. 
The distinction between the evaluation of the usability and the evaluation of the utility of digital environments is wide and needs some more explanations.

In fact, the first macro-criterion is mostly independent from the quality of content, depending on the ease of use and learnability of user interface. A synthetic but effective definition of usability could be the one provided in the ISO/DIS 9241-11 standard : « the extent to which a product can be used by specified users to achieve specified goals with effectiveness, efficiency and satisfaction in a specified context of use ${ }^{22} \gg$. The context of use is made of the context of the user, the aim or task, the hardware resources and software used, and the physical and social environment in which the product is used. Effectiveness indicates the accuracy and completeness with which the user can attain the specified results, efficiency the use of resources in relation to accuracy and completeness, while satisfaction indicates freedom from unease and obligations and a favorable tendency in the user towards the product. Adopting a usercentered approach to digital cultural heritage applications development represent a crucial requirement to ensure a high level of quality to user experiences. Usability is a field connected both with the tradition of ergonomics studies, i.e. the design (and evaluation) of products/systems based on the analysis of human factors and ergonomics issues $^{23}$, and with the HCI (Human Computer Interface) design issues, also known as software and Web usability. The methods of analysis and evaluation of usability could be classified into two levels : the expert evaluation, conducted by cognitive psychologists and HCI experts; or the so-called discount evaluation, affordable by everyone and focused on the main issues ${ }^{24}$. Here is not possible to present all the issues related with the adoption of the User Centered Design ${ }^{25}$; it is enough to remember that it is « a framework of processes (not restricted to interfaces or technologies) in which the needs, wants, and limitations of end users of a product, service or process are given extensive attention at each stage of the design process ${ }^{26} »$.

The evaluation of utility, in the sense of real satisfaction of final users against the available content, is much more a qualitative criterion, depending on the type of content, environment and mission of the application, so it asks necessarily the involvement of specific content experts. The issue of language, also present for usability, here becomes crucial and is mashed up with the content structure.

How affordable are user studies for digital cultural heritage programs? Years before the rise of the global information network, user studies were defined as an area of multi-disciplinary knowledge with the aim of studying information systems and services from the perspective of users behavior (Exon, 1978). User studies investigate the characteristics, needs, behaviors and opinions of the information systems users (potential or actual). They have as their ultimate goal the development of information

22. ISO/DIS 9241-11, Ergonomics of human-system interaction - Part 11: Usability : Definitions and concepts.

23. See ISO/TR $16982: 2002$, Ergonomics of human-system interaction - Usability methods supporting human-centered design.

24. See for example the famous method presented in Krug (2014) or Nielsen (2003).

25. User-centered design, Wikipedia, the free encyclopedia, https://en.wikipedia.org/wiki/Usercentered_design [checked on 2020, june, 10].

26. ISO 9241-210 :2010. Ergonomics of human-system interaction - Part 210: Human-centered design for interactive systems. Published 2010/03/15, last revision 2015/06/18. 
services able to respond adequately to users' requests, although for their methodologies they represent an heterogeneous set of research (Bawden, 1990). This definition has to be considered in the light of the paradigm shift of the 80s : close to the studies investigating the users of a determinate information system, a new kind of research appeared, investigating the overall system of motivations, feelings, perceptions of users in the general processes of searching for information. While the first area keeps on to be called user studies, the second one is named, at international level, information behavior or information seeking behavior (Dobreva, O'Dwyer and Feliciati, 2012).

User studies include a range of methods, which can be applied to understand better user needs and expectations (surveys, questionnaires, interviews, deep log analysis, personas, eye-tracking analysis, ethnographic studies). In synthesis, they could be classified distinguishing direct and indirect methods, focused on sample or census data, based on on-site or semi-automatic research and include expert studies and project staff involvement.

An underexplored but emerging sector of user studies is represented by the analysis of how the use of the social media could provide insights into the user interests, and how the engagement with users can be enhanced by an aware adoption of these applications (Boyd and Ellison, 2007; Duggan and Brenner, 2013). The study of users and social media is mostly technical, but of course the research questions have to be clear and posed firstly by the content experts.

To conclude this chapter, it is essential to remember that most of Web users are non-human. Digital cultural heritage online has to be conceived as « "two-headed", to ensure quality in access and use. The first head addresses software agents and has to be built on mandatory metadata to avoid ambiguities caused by blind automatisms » (Feliciati, Alfier, 2014, p. 175). Thus, user studies have to consider the important role played by software agents (robots, spiders, crawlers, data-mining agents, etc.) while using our Web environments; this field of analysis requires typically the adoption of Web analytics studies (based on specialized software) in order to verify, just to quote the first of the questions to pose), how search engines find, retrieve and index our content.

\section{Conclusions}

To sum up the issues presented above, even if we live in the age of evaluation and concurrency we have to admit that we still suffer the lack of sufficient evaluation activities, based on shared development models and quality criteria, possibly measureable, and checked with the involvement of users.

Especially in the cultural heritage sector, it is still strong the prejudiced presumption that culture has an ideal value in itself, independently by its social perception and impact. On the contrary, to guarantee a high level impact of digital cultural heritage, offered to distant users without the mediation of experts, we need a widely shared procedure for the quality evaluation. Gathering and sharing the right amount of data on the effective satisfaction of final users could have the positive effect of developing new solutions and to assess the existing environments. 
As regards systems, we surely need more cognitive studies, evidence-based models, and open-minded developers. Humanities and digital content providers should collaborate more or better, mixing the competences and going beyond the old and traditional sector boundaries, mostly not comprehensible by final users, whose profiles, behaviors, needs have to be studied more.

To close with another literary citation, it is evocative to remind what the ancient roman architect Marco Vitruvio Pollione, in his multi-volume work De Architectura ${ }^{27}$, dedicated to his patron, the emperor Caesar Augustus as a guide for building projects, wrote about the essential qualities of good architecture, utilitas (convenience), firmitas (durability) and venustas (beauty ${ }^{28}$ ). For our digital buildings, while the durability has to be based mostly on the best possible technical and organizational solutions, the convenience and the beauty depend just on the fruition of good content by any possible user, whose experience would be useful, easy and satisfactory.

\section{References}

Aveney, Brian and Conneen, Sheila (1986) « The Atomization of Information », Bulletin Medical Library Associated, No 74 (1) January 1986, p. 22-26.

Bawden, David (1990) User-oriented evaluation of information systems and services, Gower, Aldershot.

Berners-Lee, Tim ; Hendler, Jim ; Lassila, Ora (2001) «The Semantic Web», Scientific American, May 17, 2001, now in http://www.cs.umd.edu/golbeck/LBSC690/SemanticWeb.html[checked on 2020, june, 10].

Boyd, Dana M. and Ellison, Nicole B (2007) « Social Network Sites : Definition, History, and Scholarship », Journal of Computer-Mediated Communication, vol. 13, Issue 1, October 2007, p. 210-230.

Calvino, Italo (1988) Six Memos for the Next Millennium. Cambridge, Massachusetts, Cambridge University Press. For the italian edition, Id Lezioni americane. Sei proposte per il prossimo millennio, Milano, Garzanti.

Chowdhury, Gobinda G. and Chowdhury, Sudatta (2002) Introduction to digital libraries, London, Facet Publishing.

Dal Pozzolo, Luca (2015) L'impatto sociale che vorremmo », Economia della cultura, a. XXV, n. 1 p. 47-56.

Dobreva, Milena; Birrell, Duncan; Dunsire, Gordon; Griffiths Jillian; Hartley, Richard \& Menzies, Kathleen (2009) «The DiSCmap project : Digitization of Special Collections : mapping, assessment, prioritization », World Library and Information Congress : 75th IFLA General Conference and Council, 23-27 August 2009, Milan, Italy, Session 92. Statistics and Evaluation, Information Technology and Preservation and Conservation. Milan, http://www.ifla.org/files/hq/papers/ifla75/92-dobreva-en.pdf [checked on 2020, june, 11].

Dobreva, Milena; O'Dwyer, Andy; Feliciati, Pierluigi (2012) User Studies for Digital Library Development, London, Facet Publishing.

Drijfhout, Douwe (2001) «The dilemma of modern media : preserving Web publications », Journal of Librarianship and Information Science in Africa, 1(1). http://www.informationr.net/ir/15-4/paper445. html $\backslash \#$ dri01 [checked on 2020, june, 11].

27. For an open access english edition of this work, see Vitruvius (1914).

28. «Durability will be assured when foundations are carried down to the solid ground and materials wisely and liberally selected; convenience, when the arrangement of the apartments is faultless and presents no hindrance to use, and when each class of building is assigned to its suitable and appropriate exposure; and beauty, when the appearance of the work is pleasing and in good taste, and when its members are in due proportion according to correct principles of symmetry » (ibid., chapter III, 2). The original text, Capitulum III, 2, reads : « Haec autem ita fieri debent, ut habeatur ratio firmitatis, utilitatis, venustatis. Firmitatis erit habita ratio, cum fuerit fundamentorum ad solidum depressio, quaque e materia, copiarum sine avaritia diligens election; utilitatis autem, <cum fuerit $>$ emendata et sine inpeditione usus locorum dispositio et ad regiones sui cuiusque generis apta et commoda distribution; venustatis vero, cum fuerit operis species grata et elegans membrorumque commensus iustas habeat symmetriarum ratiocinationes ». (Vitruvius, De architectura libri decem). 
Duggan, Maeve; Brenner Joanna (2013) The demographics of social media users, 2012, vol. 14. Washington, DC : Pew Research Center's Internet \& American Life Project.

Exon, Andy (1978) «Getting to Know the User better», Aslib Proceedings, 30 (10-11), p. 352-364.

Feliciati, Pierluigi; Alfier, Alessandro (2014) «From Access to Use. Premises for a user-centered quality model for the development of archives online », Theory and Practice of Digital Libraries - TPDL 2013 Selected Workshops, Communications in Computer and Information Science, 416; Cham, Springer International Publishing, p. 174-179.

Filacchioni, Massimiliano (2006) «Un approccio moderno alle pagine Web», AIDA Informazioni : rivista di Scienze dell'informazione, vol. 24, No. 1-2, http://hdl.handle.net/10760/10515 [checked on 2020, june, 11].

Fuhr, Norbert; Tsakonas, Giannis et al. (2007) « Evaluation of digital libraries », International Journal on Digital Libraries, 8 (1), p. 21-38.

Hazan, Susan; Hermon, Sorin (2013) European, sustainable virtual museum V-Must Research Project Deliverable V-MusT.net - D 3.2, https://www.v-must.net/sites/default/files/D3.2 \%20European_Sustainable VirtualMuseum.pdf [checked on 2020, june, 11].

Krug, Steve (2014) Don't Make Me Think : A Common Sense Approach to Web Usability, $3^{\text {rd }}$ Edition (Voices that matter), San Francisco (CA) : Pearson Education.

Manžuch, Zinaida (2009) « Monitoring digitization : lessons from previous experiences », Journal of Documentation, vol. 65 (5), p. 768-796.

Maceviciute, Elenailson Tom . (2010) «Information behaviour research and information systems development : the SHAMAN project, an example of collaboration », Information Research, 15 (4), http: //InformationR.net/ir/15-4/paper445.html [checked on 2020, june, 11].

Natale, Maria Teresa ; Fernández, Sergi ; López, Mercè (dir.) (2012) Handbook on virtual exhibitions and virtual performances, version 1.0, INDICATE and ICCU, Roma http://www.indicate-project.eu/getFile. php?id=412 [checked on 2020, june, 11].

Nielsen, Jakob (2003) Usability 101 : Introduction to Usability, Nielsen-Norman Group, http://www. nngroup.com/articles/usability-101-introduction-to-usability/ [checked on 2020, june, 11].

Patel, Manjula et al. (2003) « Digitization to Presentation : Building Virtual Museum Exhibitions », Vision, Video and Graphics 2003, Conference, Bath, http://opus.bath.ac.uk/21506/1/paper31.pdf [checked on 2020, june, 11].

Plato (380 B.C.E) Meno, or Virtue, English translation by Jowett Benjamin, http://classics.mit.edu/ Plato/meno.html [checked on 2020, june, 11].

Ramanathan, V. Guha (2013) « Light at the End of the Tunnel », Keynote speech, International Semantic Web Conference, http://iswc2013.semanticWeb.org/content/keynote-ramanathan-v-guha.html [checked on 2020, june, 11].

Tsakonas, Giannis; Papatheodorou, Christos (2008) « Exploring usefulness and usability in the evaluation of open access digital libraries », Information Processing ES Management, 44, 3 (May 2008), p. 1234-1250.

Tsakonas, Giannis (2012) «Users within the Evaluation of Digital Libraries », User Studies for Digital Library Development, op. cit., p. 51-61.

Vitruvius (70 B.C.E.) Ten Books on Architecture, translated by Morris Hicky Morgan (1914), Harvard University Press, Wikisource edition, https://en.wikisource.org/wiki/Ten_Books_on_Architecture [checked on 2020, june, 11].

Vitruvius (70 B.C.E.) De architectura libri decem, in Bibliotheca augustiana, Liber I, http://www.hsaugsburg.de/harsch/Chronologia/Lsante01/Vitruvius/vit_ar01.html [checked on 2020, june, 11]. 